\title{
Reference Values of Umbilical Artery Doppler Indices in Healthy Uncomplicated Pregnancy from 18-40 Week Gestation
}

\author{
Naila Tamkeen, Ghazala Wahid, Mehreen Samad, Nadia Khattak, Adnan Khan, Mahnoor Rehman Khan
}

\section{ABSTRACT}

Background: Doppler ultrasound in second and third trimesters is non invasive method to assess fetal wellbeing and monitoring fetoplacental unit. Normal umbilical artery Doppler indices reference values have been established in Western countries but there is paucity of studies conducted in Pakistan regarding normal umbilical artery Doppler indices reference values.

Objective: To evaluate the Doppler indices in the umbilical arteries of healthy pregnant women from 18-40 wks gestation.

Material and Methods: A cross sectional study was conducted in Radiology department of Hayatabad Medical Complex from July 2018 to Dec 2018. Total 260 normal singleton pregnancies with gestational age ranging from 18--40 weeks were included. Doppler parameters; Resistive Index (RI), Pulsatility Index (PI) and the systolic to diastolic ratio(S/D) were recorded.

Results: The normal umbilical artery Doppler indices at different gestational ages in healthy pregnant women were analyzed. Percentile values were calculated for these indices. Median values for the pulsatility index were 1.23 at $18-20$ wks which reduced to 0.86 at $39-40 \mathrm{wks}$, for the resistivity index median values were 0.70 at $18-20$ wks and 0.52 at $39-40$ wks. Systolic/diastolic ratio was 4.16 at $18-20$ wks and 2.21 at 39-40 wks.

Conclusion: In normal healthy pregnancies, doppler ultrasound should be used to evaluate the degree of feto-placental blood flow in order to detect the risk of pregnancy complications. Our study results can form a baseline for Doppler indices in second and third trimester which can further help in abnormal values in high risk patients.

Keywords: Doppler ultrasound, Dopplerindices, Normal pregnancy, Umbilical artery;

This article may be cited as: Tamkeen N, Wahid G, Samad M, Khattak N, Khan A, Khan MR. Reference Values of Umbilical Artery Doppler Indices in Healthy Uncomplicated Pregnancy from 18-40 Week Gestation. J Saidu Med Coll Swat. 2021;11(2): 63-67

\section{INTRUDUCTION}

The umbilical artery Doppler ultrasound is non invasive and safe procedure in pregnant women ${ }^{1}$.It assesses the patho-physiology of uteroplacental circulation during pregnancy non invasively and measures resistance to fetal blood flow $^{2,3}$.

Normally umbilical artery S/D ratio decreases as the gestation advances due to increase in arterial blood flow ${ }^{4}$. There is definite proven relationship between abnormal umbilical artery doppler parameters and preeclampsia, intrauterine growth retardation and poor pregnancy outcome ${ }^{5}$.Umbilical artery Doppler velocimetry helps to assess the risk to fetus and identifies the intrauterine growth retardation which is primarily caused by placental insufficiency in healthy fetuses $^{6,7}$.

The different umbilical artery doppler indices measured during pregnancy are, peak systolic velocity(PSV), end diastolic velocity(EDV), resistive index $(\mathrm{RI})$, pulsatility index $(\mathrm{PI})$, and

Department of Radiology, Hayatabad Medical Complex,

Hayatabad Peshawar

\section{Correspondence:}

Dr. Naila Tamkeen

Department of Radiology, Hayatabad Medical Complex,

Hayatabad Peshawar

Email: naila.tamkeen@yahoo.com systolic to diastolic ratio(S/D ratio). The $\mathrm{PI}$ and $\mathrm{RI}$ are measures of resistance to flow in a blood vessel and resistance to flow in a blood vessel distal to the part being assessed at an instant in a cardiac cycle, respectively; the S/D ratio on the other hand is the ratio of the PSV to the EDV ${ }^{8}$.

Normal umbilical artery Doppler indices, reference values have been established in the developed world ${ }^{9}$. However, there are very few studies conducted in Pakistan regarding normal umbilical artery Doppler indices reference values. The umbilical artery Doppler reference values calculated in developed countries may not be appropriate in Pakistani populations due to different socio-demographic as well as a higher burden of preeclampsia. The aim of this study was to evaluate umbilical artery Doppler indices from 18 to 40 weeks of gestation in healthy women with singleton gestation. Various indices of umbilical artery Doppler were studied, such as pulsatility index $(P I)$, resistance index $(R I)$ and systolic/diastolic (S/D) ratio and their usefulness as screening tests. These doppler indices will serve as baseline values in predicting impaired blood flow velocimetry in pregnancy induced hypertension, intrauterine growth retardation and other conditions that lead to serious maternal and fetal health compromise. 


\section{MATERIALS AND METHODS}

This was a single hospital-based cross sectional study done in Radiology Department,

Hayatabad Medical Complex Peshawar from 1st July 2018 to 31st December 2018. Normal reference values of Umbilical artery Doppler in the second and third trimester of pregnancy were obtained among healthy normotensive pregnant women referred from Gynae \& Obs department, for the routine obstetrical ultrasound. This study involved assessment of umbilical artery velocimetry with color and spectral Doppler ultrasound scans.

The pregnant women at gestational ages 18-40 weeks were included in the study. The Gestational age was calculated from the last menstrual period (LMP) in patients with reliable dates. Where patients were unsure of the gestational age(GA); dating was based on the early obstetrics ultrasound done in the first trimester of pregnancy. Pregnant women with single gestation with appropriate GA, normal blood pressure (BP), tested negative for proteinuria were evaluated. The pregnant women with history of diabetes, chronic hypertension, alcohol and drug abuse, fetal anomaly, corticosteroids use, or vascular disorders that may affect Doppler measurements were excluded from the study.

A preliminary routine obstetric Ultrasound was carried out to document obstetric parameters, number of fetuses, and to rule out fetal malformations. Umbilical artery was evaluated by 5.0 $\mathrm{MHz}$ curvilinear probe on Aloka ultrasound Doppler machine by single sonologist. A free loop of umbilical cord was located with B-mode ultrasonography for consistency of measurements. The umbilical artery was identified using color Doppler. Doppler velocities were assessed in the absence of fetal movement or uterine contraction. The pulsatility index, resistive index, and systolic to diastolic ratio were measured and documented.

Data was analyzed using the statistical package for social sciences (SPSS) version 20.0.

\section{RESULTS}

Umbilical artery Doppler reference values were recorded in a total of 260 healthy single pregnancies. .The maternal age was between 16 and 43 years. Most of the patients $(52.7 \%)$ were in the 25-35 year age range while those aged 40 years and above accounted for only $4.6 \%$. (Figure No.1)
Among 260 total patients, $143(55 \%)$ were prim gravida women while $117(45 \%)$ were multigravida. (figure No.2)

Doppler parameters measured from umbilical artery in the second and third trimester are shown in Table 1, 2 \& 3. These umbilical artery Doppler indices showed significant correlation with period of gestation with significant decrease in the $S / D$, $R I$, and $\mathrm{PI}$ between the second and third trimesters scan

Median Resistive index at $18-20$ weeks of gestation was 0.70 which decreased to 0.52 at 3940 weeks of gestation.

Median Pulsatility index was 1.21 and 0.82 at 1820 and 39-40 weeks of gestation respectively.

Median value of systolic/ Diastolic ratio also decreased from 4.21 at $18-20$ weeks to 2.21 at 39 40 weeks of gestation.

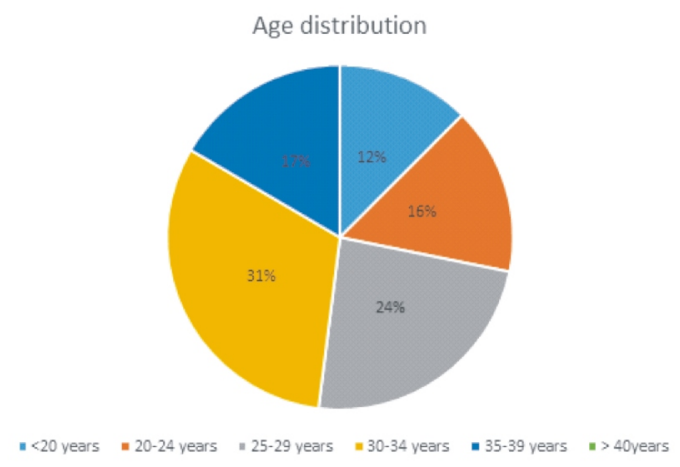

Figure No. 1

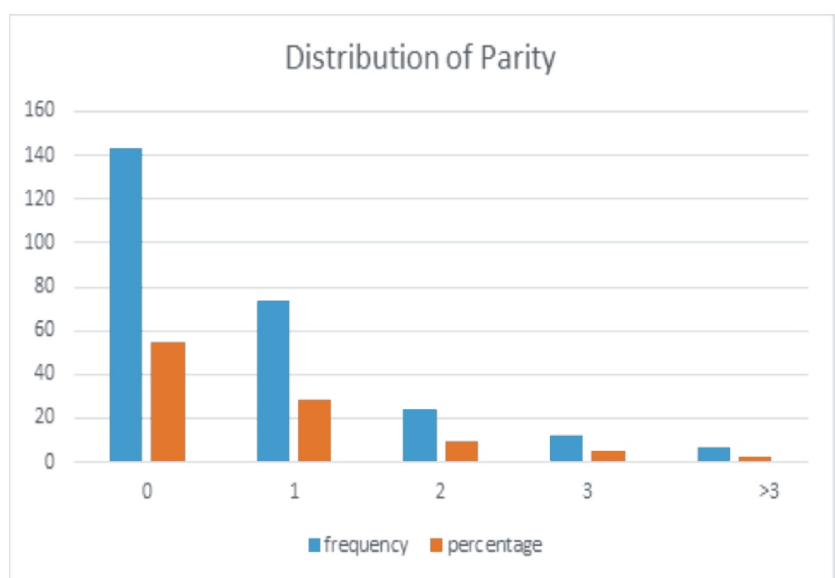

Figure No. 2 
Reference Values of Umbilical Artery Doppler Indices in Healthy Uncomplicated Pregnancy.....

Table 1: Percentile Values (5th, 50th and 90th) Of Umbilical Artery Resistive Index Obtained At Different Weeks Of Gestation.

\begin{tabular}{|c|c|c|c|}
\hline $\begin{array}{c}\text { Gestational age } \\
(\mathbf{w k s})\end{array}$ & $\mathbf{5}^{\text {th }}$ percentile & $\mathbf{5 0}^{\text {th }}$ percentile & $\mathbf{9 0}^{\text {th }}$ percentile \\
\hline $18-20$ & 0.63 & 0.70 & 0.78 \\
\hline $21-23$ & 0.57 & 0.65 & 0.75 \\
\hline $24-26$ & 0.54 & 0.64 & 0.73 \\
\hline $27-29$ & 0.49 & 0.61 & 0.72 \\
\hline $30-32$ & 0.47 & 0.59 & 0.70 \\
\hline $33-35$ & 0.45 & 0.56 & 0.67 \\
\hline $36-38$ & 0.42 & 0.54 & 0.65 \\
\hline $39-40$ & 0.40 & 0.52 & 0.60 \\
\hline
\end{tabular}

Table 2: Percentile Values (5th, 50th and 90th) Of Umbilical Artery Pulsatility Index Obtained At Different Weeks Of Gestation.

\begin{tabular}{|c|c|c|c|}
\hline $\begin{array}{c}\text { Gestational age } \\
(\mathbf{w k s})\end{array}$ & $\mathbf{5}^{\text {th }}$ percentile & $\mathbf{5 0}^{\text {th }}$ percentile & $\mathbf{9 0}^{\text {th }}$ percentile \\
\hline $18-20$ & 0.92 & 1.23 & 1.52 \\
\hline $21-23$ & 0.89 & 1.18 & 1.47 \\
\hline $24-26$ & 0.85 & 1.13 & 1.39 \\
\hline $27-29$ & 0.78 & 1.06 & 1.35 \\
\hline $30-32$ & 0.75 & 0.99 & 1.29 \\
\hline $33-35$ & 0.70 & 0.96 & 1.25 \\
\hline $36-38$ & 0.65 & 0.92 & 1.18 \\
\hline $39-40$ & 0.56 & 0.86 & 1.09 \\
\hline
\end{tabular}

Table 3: Percentile Values (5th, 50th and 90th) Of Umbilical Artery S/D Ratio Obtained At Different Weeks Of Gestation.

\begin{tabular}{|c|c|c|c|}
\hline $\begin{array}{c}\text { Gestational age } \\
\text { (wks) }\end{array}$ & $\mathbf{5}^{\text {th }}$ percentile & $\mathbf{5 0}^{\text {th }}$ percentile & $\mathbf{9 0}^{\text {th }}$ percentile \\
\hline $18-20$ & 2.89 & 4.16 & 5.91 \\
\hline $21-23$ & 2.62 & 3.75 & 5.40 \\
\hline $24-26$ & 2.38 & 3.38 & 4.79 \\
\hline $27-29$ & 2.09 & 3.00 & 4.26 \\
\hline $30-32$ & 1.93 & 2.74 & 3.90 \\
\hline $33-35$ & 1.76 & 2.50 & 3.61 \\
\hline $36-38$ & 1.52 & 2.36 & 3.45 \\
\hline $39-40$ & 1.48 & 2.21 & 3.27 \\
\hline
\end{tabular}

\section{DISCUSSION}

Normal fetal growth depends on adequate blood flow through the fetal and uteroplacental circulation. Reduced perfusion is related with intrauterine growth retardation and fetal hypoxia, which is the major cause of adverse pregnancy outcome $^{10}$.The umbilical artery Doppler is a noninvasive method of evaluating the uteroplacental hemodynamic and obstetric risk assessement ${ }^{11}$. In most of studies the reference values for the umbilical artery Doppler indices are obtained from the free loop of the cord. Free loop of the cord is the easiest site to calculate the Doppler indices precisely even by less experienced sonologist ${ }^{12}$.

In this Cross-sectional study, Reference values for three umbilical artery Doppler parameters were obtained from free loop of cord by transabdominal approach performed on 260 gravid uncomplicated singleton gestation between 18 and 40 weeks. 
All three Doppler parameters calculated from free loop of the cord showed significant decrease with advancing gestational age which confirms previous observation. The results of this study are compatible to those of Antonio AGD et al and Srikumar et al who also showed the decrease in the umbilical artery Doppler indices with increasing gestational age ${ }^{12,13}$. These decrease in Doppler indices is due to decrease in placental flow resistance with advancing gestational age which is essential for the normal growth of the fetus.

In our study, Resistive index showed significant decline with increasing gestational age. This finding is similar to the study done by Kurmanavicius et al who found median Resistive index of 0.66 at 30 weeks of gestation and 0.59 at 37 weeks $^{14}$. Peudal S et al found median RI of 0.2 and 0.56 at 31 and 37 wks respectively ${ }^{11}$. Merz E et al calculated median Resistive index of $0.67,0.60$ and 0.55 at 22,30 and 37 weeks respectively ${ }^{15}$. The result of these studies are comparable to the median values of RI in our study. Similar results were showed in Ganesh Acharya et al study ${ }^{16}$ in which the Doppler indices progressively decreased with advancing gestational age.

Pulsatility index also decreased continuously with increase in gestational age in our study which is similar to previous studies. Reference values of Pulsatility index in our study are similar to the results of Peudal S et al who found median PI of 0.96 and 0.80 at 31 and 37 wks respectively ${ }^{11}$. Median Pulsatility index values were 1.16,1.01 and 0.89 at 22,30 and 37 weeks respectively in study done by Merz et $\mathrm{al}^{15}$. Acharya $\mathrm{G}$. et al found median Pulsatility index of $0.95 \& 0.80$ at $30 \& 37$ weeks respectively ${ }^{16}$. In comparison to a study on PI of umbilical artery of Israeli population our median $\mathrm{PI}$ values are slightly lower ${ }^{17}$. A study conducted by Tay et al compared uterine placental indices of healthy pregnant female patients with pregnant women with pre ecamplsia and IUGR. The PI values with pregnant patients with IUGR and Pre eclampsia were significantly higher as compared to the control group ${ }^{18}$.

Our study showed significant decrease of systolic/diastolic ratio with advancing gestational age. Our results are similar to those obtained by Peudal $S$ et al also found median S/D ratio of 2.72 and 2.30 at 31 and 37 weeks respectively ${ }^{11}$.Acharya $\mathrm{G}$. et al who found median S/D ratio of $3.77,2.75 \& 2.34$ at $22,31 \& 37$ weeks respectively ${ }^{16}$. Awan MW et al evaluated Doppler indices in normotensive and hypertensive women in the second trimester ${ }^{6}$. There mean RI and PI values are similar to our study with slight difference in S/D ratio. Median S/D ratio in our study in third trimester are similar to study by Yousaf et $\mathrm{al}^{19}$, however insignificantly raised $\mathrm{PI}$ are observed in our study. Ghosh M.et al and Ghosh $S$. et $\mathrm{al}^{20,21}$ studied the role of umbilical artery Doppler indices to compare outcome in normal dated and postdated pregnancies. No statistical significance was observed between the 2 groups.

Limitation of our study is that it was done in a single center which could have affected the results. Secondly this small sample size per gestational age, we believe, may have limited the generalizability of their results. A relatively larger sample size at those categorical gestational age should be evaluated in future studies to improve generalizability of the result.

\section{CONCLUSION}

Umbilical artery Doppler indices in our study population of normal pregnant female patients are comparable to published reference values from other studies. These reference values can helpful in the detection and management of at-risk gestations with abnormal vascular changes associated with impaired placentation in preeclampsia, intrauterine growth retardation and other conditions that are more common among Asian women. Future studies will be necessary to provide data which will study the relationship between Gestational age, parity, maternal age and other similar parameters in our population.

\section{REFERENCES}

1. Pepe P, Motta L, Pennisi M, Aragona F. Functional evaluation of the urinary tract by colour doppler ultrasonography $(C D U)$ in 100 patients with renal colic. Eur J Radiol 2005; 53:131-5.

2. Ertan AK, Tossounidis HL, Schmidth W. Normal fetomaternal doppler indices in the second and third trimester of pregnancy.IN: Schmidth W, kurjak A(edi). Colour Doppler sonography in Gynecology and Obstetrics. New York: Thieme 2005; 129-33.

3. Fatima B, Yusuf S, Mahmood RA. Validity of Umbilical Artery Doppler Ultrasound in Diagnosis of Intrauterine Growth Restricted Fetuses. Journal of Rawalpindi Medical College 2015; 19(2):140-142.

4. Trudinger BJ. Doppler ultrasonography and fetal well being. IN: Reece EA Hobbibs JC Gand NF(edi). Clinical Obstetrics; The fetus and mother 3rd ed. New York:.Black well publishing Ltd 2007;191-20.

5. Campbell S, Soothill P. Detection and management of intrauterine growth retardation: A British approach. In: Chervenak FA, Isaacson GC, Campbell S, editors. Ultrasound in Obstetrics and Gynaecology. Vol. 2. Boston: Little, Brown and Company; 1993;1431-5. 
6. Awan MW, Amjad M, Yasrab, Ather S, Ahmed A. Comparison of Fetal UmbilicalArtery Doppler Indices between Normal and Hypertensive Pregnant Women in the Second Trimester of Pregnancy. Ann Pak Inst Med Sci 2015; 11(2): 95-99.

7. Lackman F, Capewell V, Gagnon R, Richardson B. Fetal umbilical cord oxygen values and birth to placental weight ratio in relation to size at birth. Am J Obstet Gynecol 2001; 185: 674-82.

8. Bower S, Schuchter K, Campbell S. Doppler ultrasound screening as part of routine antenatal scanning: Prediction of pre-eclampsia and intrauterine growth retardation. Br J Obstet Gynaecol 1993; 100: 989-94.

9. Gomez O, Figueras F, Fernandez S, Bennasar M, Martinez JM, Puerto $B$, et al. Reference ranges for uterine artery mean pulsatility index at 11-41 weeks of gestation. Ultrasound Obstet Gynecol 2008; 32:128-32.

10. Chouhan S, Ajmera S, Vijaykumari, et al. Doppler assessment in pregnancy induced hypertension and usefulness of Doppler in predicting foetal outcome. J Evid Based Med Healthc 2018; 5(4): 339-344.

11. Paudel S, Lohani B, Gurung G, Ansari MA, Kayastha P. Reference values for Doppler indices of the umbilical and fetal middle cerebral arteries in uncomplicated third trimester pregnancy. Journal of Institute of Medicine 2010; 32(3): 25-31

12. Costa AGD, Filho FM, Spara P, Gadelha EB, Netto PVS. Fetal hemodynamics evaluated by Doppler velocimetry in the second half of pregnancy. Ultrasound Med Biol . 2005; 31:1023-1030.

13. Srikumar S, Debnath J, Ravikumar R, Bandhu HC, Maurya VK. Doppler indices of umbilical and fetal middle cerebral artery at $18-40$ weeks of normal gestation: a pilot study. Medical journal of armed forces of India 2017;73:232-241.

14. Kurmanavicius J, Florio I, Wisser J, Hebisch G , Zimmermann R, Muller R, et al. Reference resistance indices of the umbilical, fetal middle cerebral and uterine arteries at 24-42 weeks of gestation. Ultrasound Obstet Gynecol.1997; 10 (2):112-120.

15. Merz $E$ (ed): Ultrasonography in Obstetrics and Gynecology, vol 1. Stuttgart,New York, Thieme 2005: 469-480.

16. Acharya G, Wilsgaard T, Berntsen GKR, Maltau JM. Reference ranges for serial measurements of umbilical artery Doppler indices in the second half of pregnancy. Am J Obstet Gynecol 1995; 192: 937-944.

17. Zohav E, Zohav E, Rabinovich M, Alasbah A, Shenhav $\mathrm{S}$, Sofer $\mathrm{H}$ et al. Third trimester Reference Ranges for Cerebroplacental Ratio and Pulsatility Index for Middle Cerebral Artery and Umbilical Artery in Normal-growth Singleton Fetuses in the Israeli Population. Rambam Maimonides Med J 2019;10 (4):e0025. doi:10.5041/RMMJ.10379.

18. Tay J, Masini G McEniery CM, Giussani DA, Shaw CJ, Wilkinson IB et al. Uterine and fetal placental Doppler indices are associated with maternal cardiovascular function. Am J Obstet Gynecol 2019;220:96.e1-8.

19. Yousaf M, Khadija S, Bacha R, Shams MA, Zain ul abidin S. umbilical artery Doppler waveform at term. Donald School Journal of Ultrasound in Obstetrics and Gynecology 2018;12(2):104-107.

20. Ghosh M, Biswas R, Dutta SS, Pal R, Pal A. Role of middle cerebral artery and umbilical artery Doppler velocimetry studies to compare the outcome in postdated and normal dated pregnancies in a rural population of eastern India. International Journal of Biomedical Research 2018;9(1):1-7.
21. Ghosh S, Mohapatra K, Samal S, Nayak P. Study of Doppler indices of umbilical artery and middle cerebral in pregnancies at and beyond forty weeks of gestation. International Journal of Reproduction, contraception, Obstetrics and Gynecology. 2016;5(12):4174-4179.

DATA SHARING STATEMENT: The data that support the findings of this study are available on request from the corresponding author. The data are not publicly available due to privacy or ethical restrictions.

CONFLICT OF INTEREST: Authors declared no conflict of interest.

GRANTED SUPPORT AND FINANCIAL DISCLOSURE: Nil

\section{AUTHOR'S CONTRIBUTION}

Following authors have made substantial contributions to the manuscript as under

\section{Tamkeen N:}

Concept and design of study, Collection of data, statistical analysis

Samad M: Writing of manuscript, critical review of manuscript

Khattak N, Wahid G: Analysis and interpretation of data, statistical analysis

Khan MR, Khan A:Data collection, bibliography

Authors agree to be accountable for all aspects of the work in ensuring that questions related to the accuracy or integrity of any part of the work are appropriately investigated and resolved. 